\title{
A FORMA SEM CONTEÚDO E O SUJEITO SEM SUBJETIVIDADE'
}

José Leon Crochík ${ }^{2}$

Resumo: O objetivo deste ensaio é refletir acerca da relação entre o primado da forma em nossa sociedade, que se expressa também nos âmbitos políticos e educacionais, e a formação de indivíduos pouco diferençados, no que se refere à sua sensibilidade, percepção e pensamento; tem como hipótese que a ênfase na forma, em diversos domínios sociais, em detrimento do conteúdo específico ao qual deveria se vincular contribui com a formação de indivíduos que têm dificuldades de se identificarem entre si e, por isso, de se desenvolver, sendo propensos à frieza, a uma ausência de percepção das contradições e conflitos sociais e a um pensamento basicamente adaptativo. Essa reflexão é desenvolvida tendo como referência obras de pensadores que constituíram a denominada Escola de Frankfurt, tais como T. W. Adorno, M. Horkheimer e H. Marcuse, e a Psicanálise Freudiana.

Palavras-chave: Percepção da forma. Formação do indivíduo. Escola de Frankfurt. Psicanálise.

Ao final do texto “Educação após Auschwitz", Adorno (1967/1995a) distingue os assassinos de gabinete e aqueles que seguem as suas ordens. $O$ esclarecimento e a educação, segundo o frankfurtiano, podem fazer algo para que deixem de existir os que sujam as mãos, o que parece ser mais difícil de ocorrer com os que planejam o assassinato.

Adorno se refere ao período do nazismo, mas o texto citado é escrito quase duas décadas depois, indicando que o fenômeno não se extinguiu. $O$ tipo manipula-

1 O autor recebe bolsa de Produtividade em Pesquisa do CNPq, a quem agradece por ter auxiliado na elaboração deste trabalho.

2 Agradeço a Nicole Crochick e Camila Popadiuk pela tradução do resumo deste artigo para as línguas inglesa e francesa.

Psıcologia USP, São Paulo, janeiro/março, 2010, 21(1), 31-46. 
dor descrito em "Tipos e Síndromes", capítulo assinado por Adorno na obra coletiva A Personalidade Autoritária (Adorno, Frenkel-Brunswik, Levinson, \& Sanford, 1950), parece corresponder ao assassino de gabinete, um indivíduo sem consciência moral, além da necessária para seguir a hierarquia do poder: uma consciência "extrojetada"; não se identifica com os homens, mas com as máquinas, com a produção. Do ponto de vista do fortalecimento das forças produtivas, esse tipo é muito importante para o desenvolvimento da tecnologia e de seus produtos, que dão a base para uma sociedade em que a dominação do homem pelo homem e a do homem sobre a natureza não sejam mais necessárias. Do ponto de vista político, esse tipo é importante para a preservação de uma sociedade totalitária; o manipulador desloca seus afetos dos indivíduos para o "fazer coisas"; sente prazer em manipular objetos e homens para cumprir seus objetivos, sem se perguntar acerca das implicações do que faz:

O caráter manipulador... se distingue pela fúria organizativa, pela incapacidade total de levar a cabo experiências humanas diretas, por um certo tipo de ausência de emoções, por um realismo exagerado. A qualquer custo ele procura praticar uma pretensa, embora delirante, "realpolitik". Nem por um segundo sequer ele imagina o mundo diferente do que ele é, possesso pela vontade de "doing things", de fazer coisas, indiferente ao conteúdo de tais ações. (Adorno, 1967/1995a, p. 129)

Para se desenvolver, o manipulador necessita da frieza, da negação dos afetos dirigidos aos homens. Os afetos, contudo, não deixam de existir, são deslocados. Na pesquisa sobre a personalidade autoritária, Adorno et al. (1950) indicam que esse tipo não foi dos mais frequentes na amostra estudada; considerando, contudo, as necessidades da sociedade administrada, sua frequência deve ter aumentado na população.

O assassino de rua, o que pratica diretamente o ritual do sacrifício da civilização (ver Horkheimer \& Adorno, 1947/1985), poderia ser caracterizado como aquele que tem identificações negadas: agride o que suscita os seus desejos e os seus temores. O mais frágil lembra sua própria fragilidade, quando é incentivado o tempo todo pela doutrina da sobrevivência do mais apto a ser forte. Ao atacar o mais fraco, agride a si mesmo. $O$ alvo do ataque recorda também desejos que teve de renunciar, e a agressão fortalece a renúncia. Segundo a análise que Horkheimer \& Adorno (1947/1985) fizeram do antissemitismo, o judeu lembra a seu inimigo a possibilidade de viver sem fronteiras, sem pátria: ser recebido em qualquer lugar como em sua casa; a possibilidade de ser indivíduo; a possibilidade de viver sem trabalhar; a união imediata com o outro; e como "adaptado inadaptado" lembra ao gentio a própria renúncia desse último como preço à adaptação total à coletividade. 
Se o manipulador pode ser caracterizado como aquele que parece prescindir de identificações e o assassino de rua como o que tem identificações negadas, podemos pensar que o primeiro é mais regredido psiquicamente do que o último. Tal como na distinção entre a neurose e a psicose, a diferença entre ambos deve ser de grau: a partir de certo ponto das identificações negadas, haveria a negação de qualquer identificação. Se isso procede, em ambos os casos, houve em algum momento o estabelecimento de identificações que foram negadas em maior ou menor grau ${ }^{3}$. O sofrimento, assim, estaria presente nos dois tipos; a negação da identificação e a identificação negada são formas de defesa psíquica frente às ameaças existentes;"preço cobrado" pela adaptação.

Desde logo, cabe sublinhar que a constituição subjetiva provém das condições objetivas; segundo Adorno (1955/1991), a sociedade a cada época produz os homens necessários à sua reprodução; nem por isso, contudo, o entendimento do objeto - no caso, o indivíduo - deve ser reduzido à determinação social. Deve-se também assinalar que se a diferença entre o criminoso e o não criminoso é que o último conseguiu reprimir o impulso (ver Horkheimer \& Adorno, 1947/1985); o tema em discussão neste texto diz respeito à constituição de todos os homens. Pode-se estranhar o fato deste texto discutir a formação de assassinos propícios ao fascismo, posto que atualmente é predominante a defesa à democracia formal; no entanto, como, segundo Adorno (1967/1995a), as condições objetivas propícias à perseguição de minorias não deixaram de existir, há de se pressupor que a formação de indivíduos motivados à perseguição, agressão e extermínio continue a ocorrer, e, assim, em determinadas situações eles devem continuar a agir.

Como se trata da formação dos indivíduos, sempre dependente das condições objetivas, é necessário firmar a sua relação com a adaptação e com o crime, assim como com a possibilidade de autonomia. Se a formação pode ser definida pela interiorização da cultura (Adorno, 1959/2004), e se essa última tem como uma de suas fortes tendências atuais se expressar como mercadoria, ambas - a formação e a cultura - perderam a sua relativa autonomia. A formação do indivíduo por meio dessa perspectiva cultural - redução da cultura a mercadoria - seria propícia não ao desenvolvimento de uma interioridade, mas à contínua exteriorização ou projeção, posto que a identificação forjada com as imagens da publicidade que não se distinguem mais das mercadorias é, no capitalismo, voltada à reprodução do capital: ou como reprodução da força do trabalho ou como ampliação do lucro, e não objetiva que o indivíduo se torne diferente do que já é. Se a indústria cultural visa, de acordo com Horkheimer e Adorno (1947/1985), a conformação do indivíduo com o existente e com isso a reprodução da so-

3 A distinção entre identificações negadas e negação de identificação surgiu a partir de conversas com Diana Oliva, aluna do curso de Mestrado em Psicologia Escolar e do Desenvolvimento Humano do Instituto de Psicologia da USP. 
ciedade atual, a formação desse indivíduo deve ser limitada na percepção, na cognição e na sensibilidade.

Numa sociedade na qual indivíduo e sujeito não coincidem, na qual o indivíduo não pode ser sujeito, por mais que a responsabilidade de seus atos recaia sobre si, a percepção, o pensamento e a sensibilidade são restringidos. As condições objetivas tornam o homem capaz de uma percepção, um pensamento e uma sensibilidade independentes de objetos. Diferentemente do que Kant (1781/1991) descrevia acerca das categorias da estética e do pensamento humano que não poderiam ser sem a experiência com os objetos, não podendo, portanto, ser pensadas em si mesmas, hoje as formas são palpáveis, ganharam características de objetos.

O primado da forma em nossos dias, ou a tendência predominante de formalização, não é independente da razão instrumental, definida por Horkheimer (1946/1976), e faz parte da ideologia da sociedade industrial, analisada por Marcuse (1964/1982). Esse primado se expressa por leis, regras, normas, princípios, que subsumem a si toda particularidade dos objetos, procurando amoldá-los; não considera a sociedade como sua determinante, em vez disso, idealisticamente, põe-se no lugar daquela como princípio necessário à convivência social:

No entanto, a paixão pela formalização, hoje por toda parte predominante, em geral omite que ela tem ao mesmo tempo a tendência a em grande medida se distanciar do interesse específico pela sociedade concreta vigente. Podese mesmo afirmar que toda a questão da formalização depende de sua parte do crescente caráter formal, isto é, do caráter funcional abstrato da sociedade, mediante o qual a formalização aparece menos como uma meta ou um ideal, mas antes como problema da sociologia. Naturalmente a formalização possui laços estreitos com a instrumentalização, ou seja, com a crença de que a constituição de instrumentos de pesquisa altamente elaborados garante por si a objetividade, em geral paga com a perda do conteúdo e que retém apenas um resíduo relativamente diluído dos fenômenos que realmente importam. (Adorno, 1968/2007, p. 168)

A percepção do mundo é reduzida às formas existentes, tarefa cumprida com êxito pela indústria cultural, que molda o mundo a ser apresentado segundo as conveniências de seus patrocinadores; o pensamento é reduzido à matemática, a fórmulas, a estereótipos, mas isso, obviamente, não é percebido: a acusação àqueles que contrapõem o socialismo ao capitalismo, ou aos que descrevem a atual sociedade como totalitária, de que veem o mundo em preto e branco é própria daqueles que defendem, sem perceber e sem entender, o horror.

A fusão entre cultura e sociedade, pela regressão da primeira à racionalidade da última, dificulta a crítica ao existente, uma vez que a crítica não pode prescindir da distância ao que é criticado; se essa distância foi 
reduzida pela afirmação do que há, a perspectiva de se entender historicamente um objeto tem dificuldades de se desenvolver. A crítica se reduz à possibilidade do aperfeiçoamento do existente, de aperfeiçoar os mecanismos de dominação existentes: o indivíduo considerado capacitado é o que consegue aumentar o controle sobre a natureza, sobre os outros homens e sobre si mesmo.

A fragilidade da constituição do eu, indicada por Horkheimer e Adorno (1947/1985) e por Adorno (1955/1991, 1967/1995a), fruto de necessidades sociais, implica uma compreensão imediata da vida em sociedade, à qual tem de se adaptar, compreensão essa sempre exterior ao próprio indivíduo. Não é casual, assim, a análise feita por Horkheimer e Adorno (1947/1985) acerca do antissemita que expressa o sujeito sem subjetividade:

O comportamento antissemita é desencadeado em situações em que os indivíduos obcecados e privados de sua subjetividade se vêem soltos enquanto sujeitos. Para as pessoas envolvidas, seus gestos são reações letais e, no entanto, sem sentido, como as que os behavioristas constatam sem interpretar. (p. 160)

Inspirada por Freud (1921/1993), essa citação indica que a regressão é ainda maior do que a descrita por ele: não se trata somente da perda momentânea dos comportamentos civilizados do indivíduo quando atua em massa, mas da desindividualização:

O "empobrecimento" psicológico do sujeito que "se entregou ao objeto", o qual "substituiu seu componente mais importante", isto é, o supereu, antecipa quase com clarividência os desindividualizados átomos sociais pós-psicológicos que formam as coletividades fascistas. Nesses átomos sociais, as dinâmicas psicológicas da formação de grupo foram para além de si mesmas e não são mais uma realidade. (Adorno, 1941/2006, p. 188)

Os indivíduos, sem atributos individuais se confundem com as massas, ao que cabe acrescentar que do período fascista até os nossos dias foram criados novos instrumentos de comunicação de massas e aperfeiçoados os já existentes, para que essas massas não precisem somente da multidão de homens solitários e frios para se constituir:o rádio, a televisão, a internet, o celular evidenciam que o "amor ao próximo" foi substituído pelo "amor a distância". O fortalecimento da "realidade virtual", não imediata, indica que a identificação não é mais com o próximo, mas com a aparência que surge fora do alcance da percepção da realidade. A cultura para ser transmitida pode dispensar seus representantes de "carne e osso", pode dispensar a identificação com o que é de fato existente, substituindo-o pela aparência, pelo que pode ser simulado: a simulação do homem substitui o homem real, o que dificulta a identificação com a autoridade, que além da 
possibilidade de tornar o indivíduo autoritário, também é propícia para o fortalecimento da individuação, como veremos mais à frente.

A subjetividade não se desenvolve mais a partir da interiorização da cultura como outrora porque a experiência, no limite, foi suprimida. A existência de um eu presente em cada reflexão que permite a continuidade e, portanto, a história individual, é substituída pela mudança contínua do indivíduo que deve se adaptar a cada nova situação abandonando o que sabia anteriormente. É mais adaptável o que não tem princípios e convicções, o que percebe as regras existentes em cada situação e as utiliza a seu favor para atingir seus objetivos, nem sempre racionais.

Esse indivíduo sem forma - que se amolda às formas exteriores - se expressa ao menos de duas maneiras: na ingenuidade e no oportunismo. $O$ ingênuo se adapta sem pensar, julgando que sua atitude não tem consequências importantes para os outros e para si mesmo; o oportunista justifica essa mesma atitude definindo que os "homens são assim mesmo", "todos têm de se virar", e, assim, deve-se, com esperteza, ludibriar os outros para se obter o que se deseja; nesse último caso, o fingimento da consciência moral, expresso por um pretenso arrependimento, propicia maior durabilidade às suas ações, e é também a adaptação ao que se supõe ser necessário; já o oportunista que não apresenta nenhum resquício de moralidade, finge sabendo que seu fingimento é percebido e que, em muitas oportunidades, é compartilhado pelos demais. Esses dois tipos de oportunista não deixam de ilustrar o tipo manipulador descrito anteriormente, e são, portanto, propícios a serem "assassinos de gabinete". Os oportunistas não somente aproveitam as oportunidades que surgem - os momentos de fragilidade dos outros -, como auxiliam a criá-las. O personagem "lago", da obra Otelo, de Shakespeare, os ilustra bem. Diferente dele, no entanto, a tragédia não recai sobre os atuais "fabricantes de intrigas": a traição não é mais condenada como antes, é aceita como algo próprio das regras do jogo da sobrevivência.

A formação do indivíduo ocorre na relação sujeito-objeto, e a distinção entre esses dois polos e a predominância de um deles sobre o outro apresentam problemas na sua constituição. Na diferenciação entre duas formas de falsa projeção, descritas por Horkheimer e Adorno (1947/1985), e na distinção entre duas possibilidades de pseudocultura discutidas por Adorno (1959/2004), esses problemas são delimitados. Quando descrevem a falsa projeção, os autores indicam a predominância do sujeito sobre o objeto - o idealismo, a paranoia - e o predomínio do objeto sobre o sujeito - o positivismo. No primeiro caso, o indivíduo projeta sem controle sobre o objeto, esse é só ocasião de seu delírio; no segundo, o controle da projeção só permite a reprodução do que é percebido. $O$ verdadeiro conhecimento deveria ocorrer pelo movimento conjunto da projeção e seu controle: 
A profundidade interna do sujeito não consiste em nada mais senão a delicadeza e a riqueza do mundo da percepção externa. Quando o entrelaçamento é rompido,o ego se petrifica.Quando ele se esgota, no registro positivista de dados, sem nada dar ele próprio, se reduz a um simples ponto; e se ele, idealisticamente, projeta o mundo a partir da origem insondável de si mesmo, se esgota numa obstinada repetição. Nos dois casos, ele sacrifica o espírito. Só a mediação, pela qual o dado sensorial vazio leva o pensamento a toda a produtividade de que é capaz e pela qual, por outro lado, o pensamento se abandona sem reservas à impressão que o sobrepuja, supera a mórbida solidão em que está presa a natureza inteira. (Horkheimer \& Adorno, 1947/1985, p. 176)

Assim, no conhecimento defendido pelo Positivismo, não há a alegada neutralidade científica, mas a negação da projeção, projeção essa representada pelo método. Horkheimer e Adorno (1947/1985) afirmam que a neutralidade científica é mais metafísica que a metafísica que derrotou, tendo em vista que com a metafísica pelo menos era possível a distinção entre o conceito e o objeto, e o primeiro tinha possibilidade de ser contrastado pelo último e ser afirmado como obra do sujeito:

A apologia metafísica deixava entrever a injustiça da ordem existente pelo menos através da incongruência do conceito e da realidade. $\mathrm{Na}$ imparcialidade da linguagem científica, o impotente perdeu inteiramente a força para se exprimir, e só o existente encontra aí seu signo neutro. Tal neutralidade é mais metafísica do que a metafísica. (p. 35)

O Positivismo é outra maneira de se pensar a forma sem conteúdo e o sujeito sem subjetividade, desta vez o sujeito esquecido de si mesmo, que não compreende, tal como Kant (1781/1991) pôde expressar, que as categorias do conhecimento são do sujeito e não se referem imediatamente ao objeto.É nesse sentido que Adorno (1969/1995) irá reaver a materialidade da epistemologia pela compreensão que o sujeito é também objeto.

$\mathrm{Na}$ descrição dos dois tipos de pseudocultura, a cisão entre sujeito e objeto e o predomínio de um sobre o outro também ocorrem. Um dos tipos de pseudocultura é a valorização da cultura como um fim em si mesmo, deslocada da necessidade de pensar e lutar por uma sociedade humana, alheia às modificações sociais necessárias para que o homem seja livre. No outro tipo de pseudocultura, a cultura se restringe à sociedade, reproduzindo-a imediatamente, mas a vida desencantada não traz felicidade para os homens, e como esses não conseguem se voltar contra o que Ihes tira o encantamento, dirigem-se a explicações mágicas e aos mitos; uma vida desencantada também é outro modo de expressão do sujeito sem subjetividade. Certamente, o desencantamento é objetivo importante do esclarecimento, mas esse deve se voltar à crítica das ilusões contidas na presença de poderes no mundo inanimado e não a retirar da vida o 
que deve ser mistério sem fim. Quando o indivíduo é estudado e analisado como objeto morto, quer seu corpo quer sua psique se petrificam; não há mais nada de novo, tudo é previsível, mas como esse conhecimento é proveniente do sujeito que também se petrificou no método, o que resta desse sujeito procura outras formas de se manifestar, não necessariamente como irracionalidade, mas como reflexo da própria objetificação, que substitui a objetivação, que só pode se expressar pelos homens em sua contínua subjetivação, posto que quanto mais o sujeito consegue se desenvolver, mais objetivo será.

Essa forma de objetivação, contudo, é coibida, conforme assinalado, com a redução da cultura à sociedade e a complementação da valorização da cultura como um fim em si mesmo. O narcisismo coletivo que essa última forma de pseudocultura representa já indica o sofrimento e o desespero existentes. $O$ mundo plenamente colonizado tornou-se ambiente inóspito, deserto: só se procura saber o que de todo modo já se sabe; as pessoas não têm mais o que conversar, pois todos são 'bem' informados e não conseguem ir muito além das informações, o que auxilia a tornar a conversa sobre a política tão superficial quanto a que inicia comentando o clima e termina maldizendo a "inevitável" corrupção humana.

Na sociedade formalmente livre, democrática, justa, as formas predominam, pondo-se no lugar dos sujeitos, que se tornam seus meios de expressão. As discussões democráticas que seguem as regras que tornam todas as manifestações equivalentes pela forma reduzem a possibilidade de julgamento, e o que é avaliado tende a sê-lo pela apreciação da aparência dada pela forma. Forma e conteúdo, no entanto, não deveriam ser dissociadas e, sim, relacionadas e confrontadas: a forma representa o sujeito que conforma o objeto do qual provém o conteúdo; nessa distinção e relação e/ou confrontação entre os dois, ambos se elucidam; quando a forma é o próprio conteúdo não há mais delimitação: o sujeito se torna objeto e buscam-se as formas mais adequadas não para o objeto ser mais bem expressado, o que permitiria a sua distinção do sujeito, mas para o sujeito expressar - como forma - o que o objeto é para si: o pragmatismo é uma ilustração disso.

O idealismo (a paranoia) e o Positivismo tornam-se visíveis em sua identidade pela apologia à forma, ainda que pareçam contrapostos. $O$ idealismo, porque, para esse, a verdade se encontra no sujeito, como se diz atualmente, em suas formas de enunciação, não importando o que é enunciado: a análise por meio de estruturas, discursos, considerados desprovidos da história, calcados nas formas das estruturas e dos discursos "falam" pelo sujeito assujeitado. O Positivismo repete para todos os objetos o mesmo método criado pelo sujeito, que não se percebe como sujeito e se esquece no método.

As discussões ditas democráticas resultam das ditaduras da forma; assim, não são democráticas. Como essas formas tentam prescindir da 
história do sujeito que as criou - a sociedade -, não consideram que esta sociedade é, em sua base, injusta, opressiva e tem como criação contínua a insatisfação. Como esses atributos da sociedade - injustiça e opressão - não são percebidos e refletidos, são reproduzidos no desenvolvimento social e, assim, quanto mais justiça, mais injustiça; quanto mais liberdade, mais opressão; quanto mais felicidade, mais sofrimento. Claro, a luta pela justiça, pela liberdade, pela felicidade, mostra a possibilidade da existência de uma sociedade que as promova, mas a percepção de que isso depende da iniciativa dos sujeitos, esquecendo-se das condições objetivas, leva ao abismo. Não é menos visível que nesta sociedade há também alguma justiça e liberdade, mas são exceções que confirmam a regra da injustiça e da opressão. Se esta sociedade fosse livre e justa, bastaria aperfeiçoá-la; se for assim, não nos distanciamos do discurso do Liberalismo.

Mas não, a percepção da injustiça social é flagrante. Não é possível deixar de perceber o fosso existente entre o poder dos mais ricos e o poder dos mais pobres. Um país como o Brasil, no qual a distância entre o menor salário e os maiores rendimentos é imensa, leva a pensar se um homem pode valer tanto mais do que outro. Hoje como outrora sabemos que ter dinheiro - que ou é obtido por herança ou pela sobrevivência do mais apto - pode ser a diferença entre a liberdade e a prisão: há os que podem pagar escritórios de advocacia para defendê-los e há os que não podem, e devem se conformar com o que o estado pode proporcionar; pode também ser a distinção entre a vida e a morte: há aqueles que podem pagar por bons médicos e hospitais e os que não podem. Além disso, como alegava Marx (1844/1978), o capital torna o feio bonito, o incapaz capaz, o sem inteligência inteligente e vice-versa.

Se é difícil não perceber essas contradições, o próprio sujeito deve refrear sua percepção e colocar a contrária em seu lugar: a de que o mundo é justo e que só depende dos homens o seu destino. Para isso, não basta se conformar com o mundo que é apresentado pela indústria cultural, devese defendê-lo. Uma tal consciência contraditória e seu resultado obrigam o indivíduo a afastar da consciência as contradições e pôr o discurso da competência individual em seu lugar, mas como a contradição é forte, a convicção no discurso é frágil e para se solidificar precisa cada vez mais negar as contradições. Esse movimento vai se acirrando até chegar ao fanatismo pelo mundo existente. Os "crentes" não podem ter sua fé posta em questão, e assim a sua irritação é reação natural aos que se contrapõem e fazem críticas a esta sociedade; e se irritam, pois têm em sua própria consciência, por mais que a neguem, a percepção da injustiça da qual são alvo e que reproduzem sobre os outros. O pseudoformado é identificado por tentar a todo o momento se livrar da culpa e da consciência de ser medíocre, ou pela projeção da própria mediocridade sobre os demais, ou pelas justificativas constantes de não poder ser de outro jeito. 
Mas como fazer para que os indivíduos incorporem a censura em relação à percepção das contradições? Adorno (1955/1991) argumenta que quem não segue o estabelecido, nos dias em que escreveu, o que supomos valer para os nossos dias, não é mais morto, nem posto nas masmorras, mas é deixado de lado, à margem; $a$ ameaça continua a existir. $O$ apego aos bens da civilização ocorre por formação reativa: aprende-se a amar o que antes era, na melhor das hipóteses, desprezado. E isso ocorre mediado pela angústia - o medo criado independentemente do perigo, que nos alerta contra ele. O comportamento dirigido ao lucro é mediado pela angústia, que, por sua vez, também é mediada. Essa provém do medo de sermos expulsos da coletividade que nos protege dos perigos, que está associado ao medo da destruição:

Más esencial resulta, como motivo subjetivo de la racionalidad objetiva, la angustia. Una angustia mediada. Hoy en día, quien no se comporta según las reglas económicas raramente se arruina al momento. Pero en el horizonte apunta el desclasamiento. Se vuelve visible el camino que lleva a lo asocial, a lo criminal: rehusarse a participar en el juego hace sospechoso, y expone a la venganza social incluso a quien no necesita pasar hambre ni dormir bajo los puentes. Pero la angustia a ser expulsado, la sanción social del comportamiento económico, se ha interiorizado hace mucho junto con otros tabúes, y ha cuajado en el individuo. (Adorno, 1955/1991, pp. 142-143)

Essa explicação complementa a que é dada por Freud (1930/1985) acerca da formação do superego que protege a sociedade de nossa violência. Freud (1930/1985) alerta que parte considerável dos homens não desenvolve o superego e, nesse mesmo sentido, podemos pensar que, se os indivíduos constituem um eu frágil, dificilmente terão uma consciência moral bem estabelecida; assim os homens executam ou não o que é proibido, dependendo da presença ou ausência da autoridade. Mas a autoridade, segundo Marcuse (1955/1981), torna-se cada vez mais impessoal, assim ela está sempre presente, ainda que não de forma plenamente visível.

Em relação à autoridade, deve-se assinalar, em primeiro lugar, que é importante para a formação do indivíduo, pois é por meio da incorporação dos valores, princípios, modos de agir da autoridade, mediada pela forma como o indivíduo a percebe, e pelo contraste percebido entre o que é a autoridade incorporada como um ideal e o que se contrapõe a esse ideal, que se constitui o indivíduo. A autoridade tradicional (pai, professor), contudo, foi enfraquecida na passagem da sociedade liberal para a sociedade administrada, mas como a necessidade da autoridade não declinou tal como a própria autoridade, os líderes que aparecem são seus substitutos. Como devem representar a capacidade de cumprir os desejos e necessidades dos adeptos, devem ser tal como esses últimos e ao mesmo tempo cúmplices de um poder mais elevado, e, da mesma forma que o"pequeno 
grande homem" (ver Horkheimer \& Adorno, 1947/1985), guardam numa única referência os dois vínculos grupais descritos por Freud (1921/1993): o vertical, o líder que os indivíduos põem no lugar do ideal do eu, e o horizontal, que permite a identificação entre os que se vinculam ao mesmo líder. Mas hoje, como um processo que prossegue a despersonalização dos líderes, que já era próprio do fascismo alemão, no qual os representantes do poder eram muitos e podiam ser facilmente substituídos, a autoridade não depende das características individuais dos líderes, esses representam o poder enquanto tal, não se diferenciando entre si. As diversas formas de autoridade representam sempre o mesmo: a aparência de que o indivíduo importa e a racionalidade que indica a adaptação ativa. Assim, se a autoridade pessoal se enfraqueceu, a sua força se diluiu para as diversas pequenas autoridades que representam sempre o mesmo. Como na colmeia das abelhas, na qual são forjadas as operárias para se tornarem rainhas quando for necessário, os indivíduos são formados para se adaptar a uma estrutura social hierárquica, na qual todas as posições são substituíveis.

Se os indivíduos devem ser substituíveis na hierarquia social, seu ego não deve mesmo se desenvolver para além do cativeiro que implica essa hierarquia. Mas voltando à questão anterior, a autoridade não deixou de existir, ela tornou-se ao mesmo tempo mais distante e mais próxima: mais distante, porque impessoal e até invisível; mais próxima, porque pode ser assumida por todos, e tal como na horda primeva descrita por Freud (1921/1993), os diversos filhos estão prontos para ocupar o lugar do 'pai': preparam-se em segredo, manifestando obediência e servilidade aparentes ao líder da ocasião, para derrubá-lo e tomar o seu lugar. A questão, como Marcuse (1955/1981) mostra, não é o fim da autoridade, mas que ela é reposta, impedindo que a liberdade possa surgir. Assim, a cada nova rebelião bem-sucedida, o poder anterior retorna, sob nova forma, mas fortalecido (ver Marcuse, 1955/1981).

De um lado, como argumentam Horkheimer e Adorno (1947/1985), a nova forma de autoridade da civilização, representada também pela justiça moderna, opõe-se à violência imediata; de outro, reproduz a própria violência ao não considerar que os homens formalmente iguais não são socialmente iguais. Se a consciência moral é "extrojetada" sobre as diversas autoridades que representam a racionalidade do sempre igual, posto que é utilizado o mesmo método de pensar independentemente do objeto, os indivíduos só podem desafogar sua fúria em momentos consentidos e estimulados socialmente, que são ilustrados pelos comportamentos da massa de indivíduos em espetáculos de futebol ou de música popular industrializada. Em outras palavras, se a forma se torna o conteúdo e é externa, estranha ao indivíduo, posto que só os conteúdos propícios à adaptação podem ser expressados, o que deveria ser o conteúdo não se forma, não encontra signos que permitam diferençá-lo. Os conteúdos não nomeados (que por isso mesmo não chegam a ser conteúdos) geram incômodo, mal- 
estar que é canalizado pela sociedade administrada para as "descargas" aprovadas socialmente. Essa questão, relacionada ao fascismo, é expressa da seguinte maneira por Horkheimer e Adorno (1947/1985): “O fascismo também é totalitário na medida em que se esforça por colocar diretamente a serviço da dominação a própria rebelião da natureza reprimida contra essa dominação" (p. 172).

A autonomia do indivíduo, contudo, pode prescindir da autoridade após a sua incorporação e superação, não antes, e a incorporação da autoridade ocorre pela identificação. Mas o problema com o qual iniciamos este texto é o da dificuldade de identificação em nosso tempo, expressada pela identificação negada e pela ausência de identificação. Se os homens não podem mais se identificar por meio de suas diferenças, mas somente por meio de uma racionalidade que de meio se converteu em fim, a identificação resultante é a negação da própria identificação. Na identificação, segundo Freud (1923/1975), nosso eu se transforma, convertendo-se no objeto, para retê-lo para si; converte-se no que não é; se todos os modelos de identificação expressam o sempre igual, isentos de experiências e, portanto, de princípios e valores, não há identificação possível, pois não há um eu com o qual se identificar. Os modelos para identificação são frágeis para permiti-la.

Se em cada fenômeno particular a sociedade como totalidade se revela, nas propostas de educação a distância é visível o processo de despersonalização dos professores e dos alunos; no tocante à autoridade do professor, a possibilidade de se confrontar o ideal, representado por ele, e o real é dificultada; se esse contraste é responsável pela autonomia do indivíduo, sem ele, não há autonomia: o indivíduo não individuado, ou o sujeito sem subjetividade, incorpora unicamente o ideal no qual pretende se tornar, sem a possibilidade de confrontá-lo. Tal como se pode depreender da análise de Freud (1921/1993), o líder (no caso, o professor virtual) ocupa o lugar do ideal do eu, e isso ocorre com os indivíduos que não têm muita diferenciação entre o ideal de eu e o eu, que são os que têm um eu fragilmente constituído.

$\mathrm{Na}$ atual educação formal,é nítido o incentivo para o desenvolvimento das competências, das habilidades, do "aprender a aprender" o que é julgado importante. Essa tendência que aparentemente é democrática, por defender alunos autônomos, que possam buscar sozinhos o conhecimento nos diversos recursos existentes, entre eles a internet, por preparar indivíduos que possam atuar de forma competente em suas vidas profissionais, auxilia na produção de sujeitos sem subjetividade. As competências e as habilidades não são neutras, dependem do que a sociedade necessita e, assim, dever-se-ia pensar a quem beneficiam em seu desenvolvimento. Certamente, como foi dito, são importantes para o indivíduo, mas para sua conformação à vida isenta de vida. A substituição do professor pelas má- 
quinas, pelos métodos, incorre na mesma crítica feita anteriormente ao Positivismo, posto que dirigem os homens à mera adaptação.

A essência do homem, conforme Adorno (1955/1991), é a diferença. Somente com ela a cultura, como representante da coletividade humana, pode diferir da coletividade de abelhas ou de formigas. Somente indivíduos formados pela cultura que possam criticá-la para que se modifique permitem a essa última continuamente se diferençar. A educação deve ser voltada para a diferenciação; as diferenças naturais, desenvolvidas na sociedade e interpretadas pela cultura, devem poder se expressar pelos instrumentos que essa última desenvolveu, assim, quanto mais rica a linguagem, mais experiências podem ser expressas e o indivíduo pode ser mais diferençado. Cada palavra implica a possibilidade da narração de experiências, que só se realizam na expressão e comunicação para os outros. Por meio dessa diferenciação entre os homens, cada qual pode reconhecer em si mesmo a potencialidade que o outro desenvolveu, que pode ser apreciada não pela redução às necessidades sociais, mas pela realização do que é próprio ao homem, quer como singular, quer como universal.

A sensibilidade deve se voltar para diferençar; se ela busca o sempre igual, converte-se em frieza. Ela não pode se desenvolver sem a percepção e sem a reflexão, mas quando essas são reduzidas ou conformadas ao existente, a aparência das relações ocupa o lugar das mesmas: máscara transparente que percebe ao que renuncia.

O impulso mimético é substituído pela falsa mimese, a identificação pela imitação. Ao longo do tempo, segundo Horkheimer e Adorno (1947/1985), somos incentivados a abandonar a tendência a representar os outros. Tal tendência de representar os outros implica a identificação. Essa só pode ocorrer pela aproximação com o objeto da identificação, mas o indivíduo obrigado a abandoná-la torna-se vazio. Nos tempos de Freud, a identificação podia ser percebida na formação; na atualidade, ela se converte na aparência da diferença que revela o sempre igual. Antes, ainda que de forma problemática, pela possibilidade da mimese, o igualar-se permitia a diferença; hoje, com a falsa mimese, a igualdade na luta pelo poder é fortalecida. Nos comícios fascistas, conforme Horkheimer e Adorno (1947/1985), a mimese só era possível quando a lealdade à ordem estava garantida: o judeu era imitado pelo líder para ser ridicularizado, o que permitia o prazer vicariante da massa representado pela gargalhada; o custo desse prazer era o ataque ao objeto imitado. $\mathrm{Na}$ atual cultura de massas, $\mathrm{O}$ frágil também é imitado, sancionando a lealdade à ordem: o imigrante, o que tem deficiência, o idoso, o homossexual, o pobre, devem sempre ser lembrados do lugar que devem ocupar; mas o alvo são todos os homens, e, assim, a ridicularização de todos deve fortalecer a impotência de cada um e a sua dependência do poder estabelecido, sem o qual, segundo a ideologia do mais forte, não conseguiria sobreviver. 
A liberdade ainda presente de resistir à reificação deve ser exaltada onde se anunciar. Uma de suas formas de expressão é a crítica que não se limita a aperfeiçoar o existente, mas que indica suas lacunas justamente onde pretende ser pleno: no falso sujeito, que como mera forma, nega o verdadeiro.

\section{The form without content and the subject without subjectivity}

Abstract: The objective of this assay is to reflect about the relation between the primate of the form in our society, that is expressed also in the educational and politicians scopes, and the formation of individuals a little bit differenced, concerning its sensitivity, perception and thought; the hypothesis is that the emphasis in the form, in many social spheres, in detriment of the specific content which would have to be associated, contributes with the formation of individuals that have difficulties in identifying between themselves and, therefore, in developing, being inclined to the coldness, an absence of perception of the social contradictions and conflicts and to a basically conformist thought. This reflection is developed having as reference workmanships of thinkers who had constituted the called School of Frankfurt, such as T.W. Adorno, M. Horkheimer, H. Marcuse and the Freudian Psychoanalysis.

Keywords: Form perception. Citizens. School of Frankfurt. Psychoanalysis.

\section{La forme sans contenu et le sujet sans subjectivité}

Résumé: Cet essai a pour but la réfléxion sur le rapport du primat du formalisme dans notre société, qui s'exprime aussi dans les champs de la politique et de l'éducation, et de la formation des individus peu differenciés par rapport à sa sensibilité, perception et pensée; l'hypothèse c'est que l'accent mis sur le formalisme dans divers domaines sociaux, au détriment du contenu spécifique auquel il devrait s'attacher, contribue à la formation d'individus en difficultés d'identification entre eux mêmes et ainsi de dévéloppement, étant penchés vers la froideur, vers l'absence de perception des contradictions et des conflits sociaux et vers une pensée purement adaptative. Cette réfléxion s'appuie sur les oeuvres des penseurs qui ont constitués I'Ecole de Frankfurt, $y$ compris T.W. Adorno, M.Horkheimer et H.Marcuse et aussi sur la Psychanalyse Freudienne.

Mots clés: Formalisme. Sujets. Ecole de Frankfurt. Psychanalyse. 


\section{La forma sin contenido y el sujeto sin subjetividad}

Resumen: El objetivo de este ensayo es reflexionar acerca de la primacía de la forma en nuestra sociedad, la cual se expresa en el ámbito político y educacional. La formación de individuos poco diferenciados, en lo referido a la sensibilidad, percepción y pensamiento, tiene como hipótesis que: el énfasis en la forma, en diversos dominios sociales, en detrimento del contenido específico del cual se debería vincular, contribuye a la formación de las personas que tienen dificultades para identificarse entre sí y, por tanto, a desarrollarse; estando propensos a la frialdad, una falta de percepción de las contradicciones y de los conflictos sociales, y un pensamiento básicamente adaptativo. Esta reflexión es desarrollada teniendo como obras de referencia pensadores que constituían la llamada Escuela de Frankfurt, tales como.T.W. Adorno, M. Horkheimer , H. Marcuse, y el Psicoanálisis Freudiano.

Palabras clave: Percepción de forma. Sujetos Escuela de Frankfurt. Psicoanálisis.

\section{Referências}

Adorno, T. W. (1991). De la relación entre sociología y psicología. In T. W. Adorno, Actualidad de la filosofia (J. L. A. Tamayo, trad., pp. 135-204). Barcelona: Paidós. (Trabalho original publicado em 1955)

Adorno, T. W. (1995a). Educação após Auschwitz. In T. W. Adorno, Educação e emancipação (W. L. Maar, trad., p. 119-138). Rio de Janeiro: Paz e Terra. (Trabalho original publicado em 1967)

Adorno, T. W. (1995b). Sobre sujeito e objeto. In T. W. Adorno, Palavras e sinais (M. H. Ruschel, trad., pp. 181-201). Petrópolis, RJ: Vozes. (Trabalho original publicado em 1969)

Adorno, T. W. (2004). Teoría de la pseudocultura. In T. W. Adorno, Escritos sociológicos I (A. G. Ruiz, trad., pp. 37-78). Madri: Akal. (Trabalho original publicado em 1955)

Adorno, T. W. (2006). A teoria freudiana e o padrão de propaganda fascista (G. Pedroso, trad.). Margem Esquerda: ensaios marxistas, 7,164-189. (Trabalho original publicado em 1951)

Adorno, T. W. (2007) Introdução à sociologia (W. L. Maar, trad.). São Paulo: Ed. da UNESP. (Trabalho original publicado em 1968)

Adorno, T. W., Frenkel-Brunswik, E, Levinson, D. J., \& Sanford, R. N. (1950). The authoritarian personality. New York: Harper and Row. 
Freud, S. (1975). O ego e o id (J. O. de A. Abreu, trad.). Rio de Janeiro: Imago. (Trabalho original publicado em 1923)

Freud, S. (1986). El malestar en la cultura. In N. A. Braustein (Org.), A medio siglo de EI malestar en la cultura de Sigmund Freud (J. L.Etcheverry, trad., pp. 22-116). México: Siglo Veintiuno. (Trabalho original publicado em 1930)

Freud, S. (1993). Psicologia de las masas y análisis del yo. In S. Freud, Obras completas (J. L. Etcheverry, trad., Vol. 18, pp. 63-136). Argentina: Amorrortu. (Trabalho original publicado em 1921)

Horkheimer, M. (1976). A eclipse da razão (S. U. Leite, trad.). Rio de Janeiro: Editorial Labor. (Trabalho original publicado em 1946)

Horkheimer, M., \& Adorno, T. W. (1985). Dialética do esclarecimento (G. A. de Almeida, trad.). Rio de Janeiro: Jorge Zahar. (Trabalho original publicado em 1947)

Kant, I. (1991). Crítica da razão pura (4a ed., V. Rohden \& U. B. Moosburger, trads.). São Paulo: Nova Cultural. (Trabalho original publicado em 1781)

Marcuse, H. (1981). Eros e civilização (A. Cabral, trad.). Rio de Janeiro: Zahar. (Trabalho original publicado em 1955)

Marcuse, H. (1982). Ideologia da sociedade industrial (G. Rebuá, trad.). Rio de Janeiro: Zahar. (Trabalho original publicado em 1964)

Marx, K. (1978). Manuscritos econômico-filosóficos -Terceiro manuscrito (J. C. Bruni, trad., pp. 7-48). In K. Marx, Manuscritos econômico-filosóficos e outros textos escolhidos. São Paulo: Abril Cultural. (Trabalho original publicado em 1844)

José Leon Crochík, ProfessorTitular do Departamento da Psicologia da Aprendizagem, do Desenvolvimento e da Personalidade do Instituto de Psicologia da Universidade de São Paulo. Rua Harmonia, 698, apto. 43. CEP: 05435-000, São Paulo, SP. Endereço eletrônico:jlchna@usp.br

Recebido em: 20/02/2009

Aceito em: 13/07/2009 